\title{
Trabalho infanto-juvenil em artigos acadêmicos de psicólogos: uma interpretação ideológica
}

\section{Child labor in academic articles by psychologists: An ideological interpretation}

Renata Lopes Costa PRADO'

\begin{abstract}
Resumo
Este estudo teve como objetivo oferecer uma interpretação do tratamento dado ao tema trabalho infantojuvenil na produção acadêmica brasileira da Psicologia. Foram analisados 29 artigos publicados entre 1985 e 2012. Contou-se, para tanto, com aportes dos estudos sociais sobre a infância, dos estudos sobre construção de problemas sociais e da produção de John Thompson sobre ideologia. No plano metodológico, buscou-se articular o método da hermenêutica de profundidade, tal como proposto por Thompson, às técnicas da análise de conteúdo. Apreendeu-se o uso de retórica dramática que estigmatiza crianças, adolescentes trabalhadores e famílias pobres. Assim, essa produção pode ser reinterpretada como ideológica na medida em que sustenta relações de dominação entre idades e entre classes sociais.
\end{abstract}

Unitermos: Infância; Psicologia; Publicações científicas e técnicas; Trabalho infantil.

\begin{abstract}
The aim of the present study was to offer an interpretation of the treatment given to the child and adolescent labor theme in the Brazilian academic production in Psychology. A total of 29 articles published between 1985 and 2012 were analyzed. The social studies about childhood, the studies regarding the construction of social problems and the production of John Thompson regarding ideology were considered. At the methodological level, we sought to link depth hermeneutics, as proposed by John Thompson, to the content analysis techniques. Weobserved the use of dramatic rhetoric that stigmatizes working children and poor families. This production can be (re)interpreted as ideological, in the sense that it supports relationships of domination between ages and social classes.
\end{abstract}

Uniterms: Childhood; Psychology; Scientificand Technical Publications; Child labor.

O tema trabalho infantil ou infanto-juvenil foi negligenciado no Brasil até o final dos anos 1980, seja pelas políticas públicas, seja pela mídia ou pela academia (Freitas, 2004; Moraes, 2007; S. Schwartman \& F.
Schwartman, 2004). A partir de então, inúmeras campanhas e ações governamentais e da sociedade civil foram empreendidas a fim de eliminar o trabalho de crianças e adolescentes antes da idade legal.

\footnotetext{
$\boldsymbol{\nabla \nabla \nabla \nabla}$
}

1 Universidade de São Paulo, Instituto de Psicologia. Av. Prof. Mello Moraes, 1721, Bloco A, Sala 168, 05508-030, São Paulo, SP, Brasil. E-mail: $<$ renata.lopescp@gmail.com>.

Artigo elaborado a partir da dissertação de R.L.C. PRADO, intitulada "O tema trabalho infantojuvenil em artigos acadêmicos de psicológicos(as): uma interpretação ideológica". Pontifícia Universidade Católica de São Paulo, 2009.

Agradecimentos: À Fúlvia Rosemberg pela orientação da pesquisa e à Carmem Lúcia Sussel Mariano pela revisão deste artigo. 
No contexto de unanimidade pela erradicação do trabalho infantil, pode ser malvisto problematizar tal discurso. Na contramão das posições dominantes sobre o tema, entretanto, investigações antropológicas, sociológicas e da Psicologia Social indicam que nem todo trabalho é nocivo à criança e ao adolescente, não sendo, portanto, seus prejuízos inerentes ao trabalho, mas relacionados a outras condições de vida de crianças e adolescentes trabalhadores, como a pobreza, o tipo e a exploração do trabalho, bem como a hierarquização das relações etárias (Madeira, 1997; Myers, 2001; Woodhead, 1999). Além disso, movimentos organizados que envolvem crianças e adolescentes trabalhadores afirmam que ações pela erradicação do trabalho infanto-juvenil, na prática, podem significar piora em suas condições de vida, porque ignoram a proteção legal por condições dignas de trabalho (The International Movement of Working Children, 1996).

Ao se questionarem as simplificações e a não problematização de discursos e campanhas contemporâneas pela erradicação de todo e qualquer trabalho realizado por crianças e adolescentes até determinada idade, não se está defendendo o trabalho infanto-juvenil, mas considerando que há grande diversidade de trabalhos, de contextos e de sentidos atribuídos por crianças, adolescentes e seus familiares em relação aos seus trabalhos. Desse ponto de vista, torna-se inadequada a proposta universalista de resposta única - a erradicação -, ao problema social do trabalho infanto-juvenil.

Considerando, por um lado, o tratamento dado ao tema trabalho infanto-juvenil como exemplar, para a melhor compreensão das relações de idade nas sociedades ocidentais contemporâneas, e, por outro, a academia como um ator privilegiado na construção de discursos e na arena de negociação de políticas sociais para a infância e a adolescência, o estudo aqui descrito teve como objetivo oferecer uma interpretação do tratamento dado ao tema trabalho infanto-juvenil em artigos acadêmicos brasileiros de autoria de psicólogos. A pergunta que orientou a pesquisa foi: a construção da categoria trabalho infanto-juvenil como problema social, tal como abordada em artigos acadêmicos de psicólogos, pode ser interpretada como produção simbólica ideológica, ou seja, estaria sustentando relações

102 de dominação?
Deve-se ressaltar que a interpretação que se segue - da ideologia - é, como afirma Thompson (2002, p.410), "arriscada, cheia de conflitos, aberta à discussão", e que não se tem a pretensão de chegar a recomendações para os pares, o que pareceria precipitado. Apesar disso, apoiadas em Thompson (2002), considera-se que a interpretação é, ela mesma, "uma intervenção em potencial nas próprias circunstâncias sobre as quais ela foi formulada"(p.414), na medida em que "levanta novas perguntas, novas questões, exige novos tipos de evidência e nova argumentação" (p.416).

Analisaram-se artigos sobre trabalho infanto-juvenil publicados, a partir de 1985, em revistas acadêmicas brasileiras. Contou-se, para tanto, com aportes dos estudos sociais sobre a infância (Corsaro, 2011; Qvortrup, 2010; Sirota, 2001), dos estudos sobre construção de problemas sociais (Best, 2007; Lahire, 2005) e da produção de Thompson (2002) sobre ideologia.

O primeiro aporte, o dos estudos sociais sobre a infância, orientou a focalização das crianças como atores sociais (Corsaro, 2011) e da infância como categoria estrutural subordinada da sociedade (Qvortrup, 2010). Em oposição aos enfoques dominantes nas ciências humanas e sociais, com esse novo campo de estudos, a criança passa de objeto de socialização a ator social, de futuro adulto a criança historicamente contextualizada. A socialização deixa de ser vista como uma questão de adaptação ou interiorização de normas e padrões sociais e começa a ser entendida como um processo de apropriação, de reprodução e de inovação. A infância, portanto, deixa de ser vista como fenômeno biológico, natural e universal, para ser entendida como construção social, variável de uma cultura para outra; deixa de ser concebida apenas como um momento precursor e passa a ser vista, também, como constitutiva e constituinte da cultura e da sociedade.

Com efeito, o debate no campo do conhecimento se desenvolve em um momento histórico, no qual a sociedade vem reconhecendo também novos direitos à infância, haja vista a Convenção Internacional sobre os Direitos da Criança, de 1989, e o Estatuto da Criança e do Adolescente, de 1990. Com os novos direitos, estudiosos têm identificado e discutido as tensões entre os direitos relativos à proteção e os relativos à participação (Rosemberg \& Mariano, 2011). Para alguns, 
o compromisso com a tradição de proteção, fundada na ideia de educação e de instrução, é o único que pode tirar a criança de sua vulnerabilidade para que tenha acesso à autonomia; já a outra corrente pede mobilização em torno dos direitos humanos para as crianças, incluindo aí o direito de participar das decisões que afetam suas vidas. Esse debate sobre direitos de proteção e de participação apresenta ramificações no debate sobre o trabalho de crianças e adolescentes. Apesar de todos evocarem o princípio do maior interesse da criança, os defensores da erradicação do trabalho infanto-juvenil, denominados abolicionistas, mobilizam-se pela perspectiva protecionista da Convenção, enquanto a "corrente centrada na criança" apoia-se no eixo libertário dela.

Outra tensão no debate sobre os direitos das crianças refere-se ao universalismo versus relativismo cultural. Políticas oficiais costumam basear-se em modelos de infância estáticos e universalizantes. Em contraste, o relativismo cultural enfatiza a ideia de que noções de infância são elas próprias socialmente construídas e variáveis no tempo e no espaço (White, 1999). Na tematização do trabalho infanto-juvenil, a corrente crítica ao abolicionismo se sustenta na observação da diversidade de culturas nacionais e locais, para as quais nem sempre haveria incompatibilidade entre infância e trabalho.

Partindo de pressupostos diferentes desses, a maioria dos discurso públicos e das políticas relacionados ao trabalho infanto-juvenil define o problema como o trabalho em si mesmo, em vez das várias formas de abuso e exploração que podem decorrer do envolvimento de crianças e adolescentes no trabalho em sociedades adultocêntricas. Neste estudo, em vez de reificarmos o trabalho como causa em si de malefícios à crianças e adolescentes, evocamos a noção de vulnerabilidade estrutural como um dos fatores que pode tornálo perigoso, abusivo e explorador.

O segundo aporte para a construção do objeto da pesquisa vem dos estudos sobre a construção de problemas sociais. Partimos da conceituação de problema social que atenta para a perspectiva de sua construção. Isto é, o objeto de pesquisa não focaliza o trabalho executado por crianças e adolescentes como prática social, mas como o trabalho infanto-juvenil é construído como problema social, mais especificamente nos discursos acadêmicos. $\mathrm{O}$ enfoque parte do pressuposto de que a delimitação de problemas sociais não tem base apenas no âmbito "objetivo": ela se baseia, também, no âmbito do simbólico. Entre esses dois planos, material e simbólico, pode não ocorrer convergência. Isso significa dizer que algumas situações são socialmente percebidas como problemas sociais, outras poderiam ser assim concebidas, mas não o são, e o que as diferencia não é, necessariamente, a relevância ou o sofrimento a que elas remetem, mas a atenção que conseguem despertar na sociedade. Essa atenção, por sua vez, é resultado de negociações entre atores sociais com possibilidades desiguais de participação nas arenas públicas, tais como: partidos políticos, governos, meios de comunicação, igrejas, movimentos sociais, organizações multilaterais, academia etc.

Sendo a atenção pública um recurso sempre escasso diante das inúmeras situações potencialmente demarcadas como problemas sociais, a dinâmica de entrada e permanência de um problema social na agenda de políticas envolve competição com outros potenciais problemas (Hilgartner \& Bosk, 1988). A retórica envolvida nessa competição constitui tema importante na literatura sobre a construção de problemas sociais e foi, também, privilegiada neste estudo. Ela se apresenta, por exemplo, por meio da representação de uma situação como novidade, urgência e, especialmente, como drama.

O interesse em problematizar a retórica usada na construção de problemas sociais decorre não apenas de eventuais ilusões criadas por expressões ou estatísticas inadequadas, mas também por seus impactos deletérios em grupos ou segmentos sociais envolvidos, por meio, por exemplo, de estigmatização. É pela via do conceito de estigma que efetuam-se conexões entre os estudos sobre retórica na construção de problemas sociais e a teoria de ideologia de Thompson (2002), tratando o estigma como uma estratégia possível de produção ideológica.

Assim, partindo da teoria de Thompson (2002) sobre ideologia - terceiro aporte teórico utilizado -, buscou-se identificar se os discursos sobre trabalho infantojuvenil analisados estariam contribuindo para produzir ou sustentar relações de dominação entre idades ou classes sociais. Isto é, se tais discursos poderiam ser considerados ideológicos, já que ideologia, para 
Thompson, pode ser definida como "... maneiras como o sentido (significado) serve, em circunstâncias particulares, para estabelecer e sustentar relações de poder que são sistematicamente assimétricas ... Ideologia, falando de uma maneira mais ampla, é sentido a serviço do poder" (Thompson, 2002, p.16)2.

\section{Método}

No plano metodológico, buscou-se articular o método da hermenêutica de profundidade (Thompson, 2002) às técnicas da análise de conteúdo (Bardin, 2002). A hermenêutica de profundidade é o método proposto porThompson para orientar investigações que pretendem oferecer interpretações sobre o caráter ideológico de formas simbólicas. Ela é um referencial metodológico amplo que compreende três fases principais. A primeira é a análise sócio-histórica e tem como objetivo a reconstrução das condições sociais e históricas de produção, transmissão e recepção das formas simbólicas, neste caso, os artigos acadêmicos brasileiros sobre trabalho infanto-juvenil. A segunda fase consiste na análise formal, que se orienta para a identificação da organização interna das formas simbólicas, com suas características estruturais, seus padrões e relações. Ela foi conduzida aqui por meio das técnicas da análise de conteúdo. Finalmente, a fase de interpretação é, ao mesmo tempo, um processo de reinterpretação, pois projeta um significado possível que pode divergir ou não daquele construído pelos sujeitos que constituem o mundo sócio-histórico. Ela parte da análise formal para propor uma construção interpretativa do que é dito.

No plano dos procedimentos, duas grandes tarefas foram enfrentadas: delimitar e localizar o corpus e estabelecer os procedimentos para a análise dos textos. Definiu-se como produção acadêmica a ser analisada aquela que atende aos seguintes critérios: constituir-se como artigo acadêmico, ter sido publicada por uma revista brasileira entre 1985 e 2012, dizer respeito ao trabalho infanto-juvenil no contexto brasileiro e ter, pelo menos, um dos autores da área da Psicologia.
Os artigos de tipo "estado da arte"foram consultados para apoiar a apreensão do contexto sócio-histórico da produção brasileira da psicologia sobre trabalho infanto-juvenil, não tendo sido, portanto, incluídos na etapa empírica da pesquisa, uma vez que o objetivo não foi analisar discursos sobre discursos acerca do trabalho infanto-juvenil, mas discursos referentes ao próprio trabalho de crianças e adolescentes.

A opção por artigos, e não por outros materiais que também pudessem representar a produção acadêmica, deu-se graças ao alto grau de controle da comunidade acadêmica e sua adequação ao tempo disponível para a realização da pesquisa associado à busca de diversidade (Calazans, 2000). Além disso, do ponto de vista do acesso, eles são documentos de domínio público, ou seja, documentos que "eticamente estão abertos para a análise por pertencerem ao espaço público, por terem sido tornados públicos de uma forma que permite a responsabilização" (Spink, 1999, p.136).

As bases de dados consultadas foram: BVSPsi; Dataĺndice (IUPERJ); Dedalus (USP); IndexPsi; SciELO e INEP. Após a primeira busca, localizou-se a dissertação de mestrado de Moraes (2007), que contém referências de busca de artigos sobre trabalho infanto-juvenil, no período 1981-2004, efetuada mediante consulta direta à coleção de periódicos de diversas bibliotecas. A relação de artigos levantada por Moraes foi, então, compatibilizada à já elaborada para este estudo, chegando-se a 29 artigos.

Articulando os pressupostos teóricos, o problema da pesquisa e as características dos artigos, definiram-se categorias de análise que possibilitassem o destaque, sistemático, dos aspectos dos textos mais significativos, de acordo com os objetivos do estudo. Em síntese, as categorias utilizadas foram: ano de publicação; tipo de pesquisa; concepção de trabalho infanto-juvenil; posição em relação ao trabalho infanto-juvenil; suas causas e consequências; faixa etária enfocada; variável sexo; variável cor/raça; variável escolaridade; tipo de atividade ou ocupação enfatizada; representação das famílias; posição dos pais frente ao trabalho das crianças; prognóstico de vida; espaço para a voz de

2 Para a formulação, o autor parte do que chamou de "concepção letente" de ideologia de Marx, identificada em “Dezoito Brumário de Luís Bonaparte" (1852), 
crianças e adolescentes; posição deles frente ao próprio trabalho; concepção de pobreza; e estratégias de ação propostas (Anexo).

\section{Resultados}

Os artigos brasileiros da Psicologia sobre trabalho infanto-juvenil parecem ainda não constituir um campo de conhecimento, dadas a fragmentação, a quase ausência de diálogo e a dispersão empírica e teórico-conceitual. O caráter dessa produção é recente: apenas um artigo foi publicado na década de 1980 e apenas quatro na década de 1990. Quase todos datam dos anos 2000 (72,41\%). Há ainda três artigos publicados já na década de 2010.

A maioria dos artigos analisados trata de relatos de pesquisa (86,20\%), todas elas de tipo "diagnóstico". Com exceção do artigo de Feitosa, M.A.F. Gomes, M.V.S. Gomes e Dimenstein (2001), no qual se investigam políticas de saúde voltadas às crianças e aos adolescentes trabalhadores, as demais pesquisas se propõem a investigar o trabalho infanto-juvenil da perspectiva dos trabalhadores e/ou de suas famílias. As perguntas que as norteiam relacionam-se com os significados do trabalho, seus impactos na construção de identidades e sua caracterização junto a populações específicas.

Na medida em que a quase totalidade dos artigos do corpus constituem relatos de pesquisa, a expectativa seria de que informações cruciais sobre os sujeitos, especialmente aquelas relacionadas a crianças e adolescentes, fossem especificadas. Este não foi o caso, porém. Omitiram-se atributos fundamentais, por vezes, com alta incidência. Além da omissão frequente da informação sobre pertença étnico-racial em pesquisas e artigos produzidos por psicólogos brasileiros, apenas dois artigos mencionam a cor/raça (Artes \& Carvalho, 2010; Stengel et al., 2002) - nota-se, com certa surpresa, a ausência de informação sobre a idade (24,13\%), o tipo de ocupação/atividade $(20,68 \%)$ e a escolaridade (41,37\%). A ausência de informações sobre atributos tão importantes, em pesquisas apoiadas em trabalho de campo, aponta para uma faceta do tratamento dado à categoria "trabalho infantil" no corpus: sua reificação.

Outra frequente omissão que encontramos entre os relatos de pesquisa analisados foi a de informações sobre cuidados éticos na realização da pesquisa (64\%), mesmo naquelas que escutaram crianças, adolescentes e seus familiares. Parece que a pesquisa em Psicologia ainda não incorporou, de modo generalizado, procedimentos éticos que vêm sendo sugeridos por pesquisadores nacionais e internacionais (Clacherty \& Donald, 2007; Ferreira, 2008; Quinteiro, 2009), quando da escuta de crianças e adolescentes, o que alimenta assimetrias nas relações de idade.

Isso se torna ainda mais grave, pois nem sempre os qualificativos atribuídos a crianças, adolescentes e seus familiares são neutros, podendo, por vezes, ser associados a estigmas de natureza moral ("marginalidade", "famílias desorganizadas", "socialização desviante", "delinquência" etc.). Perguntamo-se: quais crianças, adolescentes e familiares forneceram seu consentimento informado? Quais forneceriam tendo conhecimento sobre o eventual uso desses qualificativos? Mas, é necessário destacar que, apesar de menos presentes, nove artigos mencionam os cuidados éticos adotados (Alberto, Santos, Leite, Lima \& Wanderley, 2011; Alves et al., 2001, 2002; Cirino \& Alberto, 2009; Feitosa \& Dimenstein, 2004a, 2004b; Guerra, 2002; Oliveira \& Francischini, 2003; Stengel et al., 2002).

A presença da voz de crianças e adolescentes trabalhadores foi expressiva: identificada em $68,96 \%$ dos artigos. Entre estes, 45,00\% apresentam a posição de crianças e adolescentes em relação ao trabalho como favorável, ainda que com restrições e, em 10,00\%, como dividida entre aspectos positivos e negativos em relação ao trabalho. Tais pesquisas corroboraram resultados encontrados na literatura que costumam surpreender pesquisadores: crianças e adolescentes, com frequência, expressam gostar de trabalhar (Madeira, 1997; Woodhead, 1999).

Segundo Woodhead (1999), ouvir o ponto de vista das crianças trabalhadoras oferece um antídoto para discursos universalistas sobre normalidade, saúde e desenvolvimento. Aqui, no entanto, apesar de muitos artigos terem-nas ouvido, em geral, suas "opiniões", quando não corroboraram a posição defendida no texto, foram desconsideradas, tidas como equivocadas. Hillesheim (2001, p.112), por exemplo, afirma que"meninosemeninas parecem relutar em admitir que este [o trabalho] interfira em algum aspecto de sua vida, avaliando-o como necessário e importante para a sua formação". Outro trecho ilustrativo a esse respeito é: "Percebe-se uma inversão dos 
fatos: as crianças/os adolescentes sentem-se importantes, graças ao trabalho que realizam para a sociedade, familia, amigos evizinhos" (Sousa, 1999, p.133).

Se, por um lado, é difícil construir um quadro sobre o trabalho infanto-juvenil no Brasil e o debate nacional a ele relacionado partindo da produção acadêmica da Psicologia, o que parece haver em comum na maior parte dos discursos acadêmicos aqui analisados é a condenação ao trabalho infantil e a sustentação de sua erradicação. Ao defender que todo e qualquer trabalho desenvolvido por crianças ou adolescentes seja combatido, experiências culturais e concepções de trabalho e de infância e adolescência específicas são projetadas como parâmetros para todas as crianças e para todos os adolescentes. Na tensão universalismo versus relativismo cultural, os artigos de autoria de psicólogos brasileiros parecem, portanto, enfatizar uma noção universal de infância e adolescência. A ideia recorrente é que, com o trabalho, perde-se a infância e o desenvolvimento da criança é inevitavelmente prejudicado. Marques (1998, p.152), por exemplo, afirma:" $a$ 'adultização' da criança se dá dentro de um sistema que produz adultos fraturados, provavelmente, pelas suas próprias 'infantilizações' e adulterações personológicas ocorridas na sua trajetória de vida atual e passada".

Paradoxalmente, apesar de menções frequentes à produção de Philippe Ariès sobre a história social da infância, ou de outros autores que adotam uma abordagem de construção social, a infância é representada, em vários artigos, como uma etapa natural e universal da vida humana. Natural, pois a crítica ao trabalho é tida como independente do contexto social, da história de vida, do grupo étnico-cultural, das vozes da criança, dos projetos da família. Além disso, crianças e adolescentes são tidos como passivamente submetidos à hierarquia familiar e de idade: o discurso acadêmico analisado apresenta crianças e adolescentes trabalhando por imposição de suas famílias. Sua condição como ator social é, nesse sentido, pouco reconhecida. Felizmente, também encontram-se exceções, pois alguns textos não se referem à infância como fenômeno natural e universal, ao contrário, apontam para a diversidade de formas que ela pode assumir (Feitosa et al., 2001; Hillesheim, 2001; Martinez, 2001).

Assim como Freitas (2004) e Rosemberg e Freitas (2002) observaram, também se nota uma centralidade da ideia do trabalho infanto-juvenil como parte de um "ciclo vicioso": diversos artigos constroem uma argumentação abolicionista partindo dessa perspectiva (Campos \& Alverga, 2001; Campos \& Francischini, 2003; Cirino \& Alberto, 2009; Cosendey, 2002; Feitosa \& Dimenstein, 2004a; Guerra, 2002; Marques, 1998, 2001, 2004; Sousa, 1999; Sousa \& Alberto, 2008). É nesse sentido que podem ser compreendidos os dados relacionados ao prognóstico de vida aventado para crianças e adolescentes trabalhadores: negativo em 75,86\% dos artigos. Sob a óptica do "ciclo vicioso", a criança que, supostamente não tem infância, também não terá futuro. Nas palavras de Guerra (2002, p.90), por exemplo, "há uma anulação do sujeito. Tornam-se pessoas sem desejo, descrentes de fazer a própria história. Muitos deles, por volta dos 40 anos, sem saúde, contam com os filhos para o sustento da família. O ciclo do trabalho produtivo precoce reinicia-se".

A noção de "ciclo vicioso" parece ter como combustível importante a ideia de que as crianças que trabalham não estudam e que o fracasso escolar está associado ao trabalho, mais do que ao próprio sistema educacional ou às desigualdades econômicas e educacionais constitutivas da sociedade brasileira. Nos artigos, a escola é definida como "a grande ausência na vida dessas crianças" (Sousa, 1999, p.121) e como "espaço de desenvolvimento que é roubado, precocemente, dos pequenos trabalhadores" (Hillesheim, 2004, p.240); e o "fracasso acadêmico" entre as crianças trabalhadoras é "o resultado mais esperado" (Campos \& Francischini, 2001, p.124). Tais posições são assumidas como verdades, havendo pouca menção à literatura disponível no Brasil que complexifica a associação linear entre trabalho e abandono da escola (Madeira, 1997; Paparelli, 2004; Rosemberg \& Freitas, 2002). Foi encontrado apenas duas exceções: Stengel et al. (2002) afirmam que o trabalho não é apontado de modo geral como impedimento para a frequência escolar, e Artes e Carvalho (2010, p.71), em suas interessantes análises, confrontam o "discurso majoritário que explica os problemas de desempenho constatados entre os meninos como consequência de fatores externos à escola, em especial a inserção no mercado de trabalho".

Com uma argumentação tão generalizada, principalmente entre os que adotam a posição abolicionista, sobre a incompatibilidade entre escola e trabalho, era 
de se esperar que os artigos incluíssem informações sobre a escolaridade ou a frequência à escola na caracterização dos trabalhadores infanto-juvenis. Como dito anteriormente, no entanto, um percentual expressivo deles não apresentou informações sobre isso.

A retórica apreendida na produção aqui analisada apresenta componentes que permitem interpretá-la como ideológica. A estigmatização dos trabalhadores infanto-juvenis e de suas famílias sustenta a argumentação abolicionista desse discurso. No "ciclo vicioso" do trabalho infanto-juvenil, a família é apresentada como apoiadora do trabalho de seus filhos, ainda que envolva prejuízos. Ela é tida como responsável pela manutenção da pobreza. Do mesmo modo, concebe-se a pobreza se autorreproduzindo, sendo a relação de dominação entre classes sociais silenciada. Os dois trechos a seguir exemplificam tais afirmações: "há uma distância enorme entre o queépensado e o queé decidido em termos de políticase as realidades vividas pelas famílias, que não só apoiam, mas, muitas vezes, impõem a entrada das crianças no trabalho" (Feitosa \& Dimenstein, 2004b, p.294); e "famílias das camadas populares sentem-se na obrigação de cuidar das crianças apenas quando são pequenas" (Sousa, 1999, p.124).

Crianças e adolescentes, por sua vez, são, em geral, apresentados como vítimas, como transgressores e como não cidadãos. Seus trabalhos, independentemente de especificidades e contextos, são desqualificados como excludentes e exploradores. Silva (2001, p.104) afirma, por exemplo, que "estas crianças não aspiram a um mundo novo, com possibilidade de maior conhecimento". Outro exemplo é a afirmação de Campos e Francischini (2003, p.125): "além dos danos físicos ementais, seu trabalho também os compromete sob o ponto de vista da moral e da educação".

\section{Considerações Finais}

Muitas foram as semelhanças entre os resultados encontrados na análise dos artigos acadêmicos e nas análises desenvolvidas em outras pesquisas relacionadas a discursos sobre crianças e adolescentes proferidos por adultos na academia (Calazans, 2000) e na mídia (Andrade, 2004; Freitas, 2004). As famílias pobres são apresentadas como ineficientes e inadequadas para resolver o problema de subsistência de seus familiares; as condições de trabalho de crianças e adolescentes não são focalizadas, elas aparecem como se correspondessem ao trabalho infanto-juvenil em si, e são apresentadas para justificar sua erradicação e não a erradicação das péssimas condições de trabalho; além disso, o discurso em defesa da proteção de crianças e adolescentes pode estigmatizá-los. Semelhanças como essas, entre discursos em diferentes arenas, permitem sugerir, no caso do trabalho infanto-juvenil, que a produção acadêmica de psicólogos brasileiros tem sido impregnada pela produção midiática, cronologicamente anterior a ela.

A produção acadêmica participa da construção de problemas sociais, bem como da constituição da agenda de políticas públicas. Aos saberes da Psicologia, cabe um papel significativo na definição e na legitimação de modelos padronizados de desenvolvimento infantil e escolarização (Mollo-Bouvier, 2005). Ao se aproximar de discursos sobre trabalho infanto-juvenil prevalentes na mídia, no ativismo e nas agências multilaterais, a produção acadêmica aqui analisada parece deixar de cumprir a função que Lahire (2005) atribui ao conhecimento acadêmico: tomar os discursos ao pé da letra e mostrar suas armadilhas e contradições.

Mostrar eventuais armadilhas e contradições em discursos hegemônicos parece ser o caminho que os psicólogos brasileiros devem privilegiar para, efetivamente, contribuir para a construção de uma agenda de políticas públicas voltadas à infância e à adolescência menos desigual.

\section{Referências}

Andrade, L. (2004). Prostituição infantojuvenil na mídia: estigmatização e ideologia. São Paulo: EDUC.

Alberto, M. F., \& Santos, D. (2011). Trabalho infantil e desenvolvimento: reflexões à luz de Vigotski. Psicologia em Estudo, 16(2), 209-218.

Alberto, M. F., Santos, D., Leite, F., Lima, J., \& Wanderley, J. C. (2011). O trabalho infantil doméstico e o processo de escolarização. Psicologia \& Sociedade, 23(2), 293-302.

Alves, P. B., Koller, S. H., Silva, M. R., Santos, C. L., Silva, A. S., Reppold, C. T., et al. (2001). Brinquedo, trabalho, espaço e companhia de atividades lúdicas no relato de crianças em situação de rua. Psico, 32(2), 47-71.

Alves, P. B., Koller, S.H., Silva, A. S., Santos, C. L., Silva, M. R. Reppold, C. T., et al. (2002). Atividades cotidianas de crianças em situação de rua. Psicologia: Teoria e Pesquisa, 3(18), 305-313. 
Artes, A. C., \& Carvalho, M. P. (2010). O trabalho como fator determinante da defasagem escolar dos meninos no Brasil: mito ou realidade? Cadernos Pagu, 34, 41-74.

Bardin, L. (2002). Análise de conteúdo. Lisboa: Edições 70.

Best, J. (2007). Social problems. New York: Norton and Company.

Calazans, G. J. (2000). O discurso acadêmico sobre a gravidez na adolescência: uma produção ideológica (Dissertação de mestrado não-publicada). Programa de Estudos Pós-graduados em Psicologia Social, Pontifícia Universidade Católica de São Paulo.

Campos, H. R., \& Alverga, A. R. (2001). Trabalho infantil e ideologia: contribuição ao estudo da crença indiscriminada na dignidade do trabalho. Estudos de Psicologia (Natal), 2(6), 227-233.

Campos, H. R., \& Francischini, R. (2003). Trabalho infantil produtivo e desenvolvimento humano. Psicologia em Estudo, 1(8), 119-129.

Cirino, D. C. S., \& Alberto, M. F. (2009). Uso de drogas entre trabalhadores precoces na atividade de malabares. Psicologia em Estudo, 3(14), 547-555.

Clacherty, G., \& Donald, D. (2007). Child participation in research: Reflections on ethical challenges in the southern African context. African Journal of AIDS Research, 6(2), 147-156.

Corsaro, W. A. (2011). Sociologia da infância. Porto Alegre: Artmed.

Cosendey, E. M. V. (2002). Histórico do trabalho infantojuvenil. Revista Devir, 2(1), 21-31.

Feitosa, I. C., \& Dimenstein, M. (2004a). Escola, família e trabalho infantil: subjetividade e práticas disciplinares. Interação, 8(2), 287-296.

Feitosa, I. C., \& Dimenstein, M. (2004b). Trabalho infantil e ideologia nas falas de mães de crianças trabalhadoras. Estudos e Pesquisas em Psicologia, 2(4), 59-75.

Feitosa, I. C. N., Gomes, M. A. F. Gomes, M. V. S., \& Dimenstein, M. (2001). O trabalho precoce e as políticas de saúde do trabalhador em Natal. Estudos de Psicologia (Natal), 2(6), 259-268.

Ferreira, M. M. M. (2008). "Branco demasiado" ou reflexões epistemológicas, metodológicas e éticas acerca da pesquisa com crianças. In M. Sarmento \& M. C. S. Gouvea, (Orgs.), Estudos da infância: educação e práticas sociais. Petrópolis: Vozes.

Freitas, R. R. (2004). O tema trabalho infantojuvenil na mídia: uma interpretação ideológica (Tese de doutorado não-publicada). Programa de Estudos Pós-graduados em Psicologia Social, Pontifícia Universidade Católica de São Paulo.

Guerra, R. B. (2002). Trabalho precoce no carvão: a resposta das crianças. Revista Devir, 1(2), 77-93.

Hilgartner, S., \& Bosk, C. (1988). The rise and fall of social problems: A public arenas model. American Journal of Sociology, 94(1), 53-78.
Hillesheim, B. (2001). O trabalho e o ser-criança na vida de meninos e meninas trabalhadores(as) em lavouras de fumo. Redes, 3(6), 109-117.

Hillesheim, B. (2004). Infância e trabalho: feminino e masculino em construção. Barbarói, 20, 61-70.

International Movement of Working Children (The). (1996). Kandapur Declaration. Retrieved on July 17, 2008, from <http://www.workingchild.org/prota2.htm>.

Lahire, B. (2005). L'invention de l'illettrisme: rhétorique publique éthique et stigmates. Paris: La Découverte.

Lopes, V. L. S. (1986). Adolescência e criatividade: o trabalho precoce e suas relações com a personalidade. Arquivos Brasileiros de Psicologia, 38(4), 95-114.

Madeira, F. R. (1997). A trajetória das meninas dos setores populares: escola, trabalho... ou reclusão. In F. R. Madeira (Org.), Quem mandounascermulher? Estudos sobre crianças e adolescentes pobres no Brasil (pp.45-133). Rio de Janeiro: Record.

Marques, W. E. U. (1996). Crianças e adolescentes marginalizados: como a rua passou a ser este lugar. Trabalho e Educação, 0, 149-158.

Marques, W. E. U. (1998). Criança trabalhadora, família e identidade: desafios para o mundo atual. Trabalho e Educação, 3, 143-159.

Marques, W. E. U. (2001). Trabalho infantil e contexto sociofamiliar: considerações acerca dos resultados de um estudo relativo às infâncias (pre)ocupadas. Trabalho e Educação, 8(8), 112-131.

Marques, W. E. U. (2004). Trabalho infantil, família, identidade e saúde mental: indagações construídas diante de um fenômeno familiar transgeracional. Trabalho e Educação, 13(1), 29-42.

Martinez, A. M. (2001). Trabajo infantil y subjetividad: una perspectiva necesaria. Estudos de Psicologia (Natal), 2(6), 235-244.

Myers, W. E. (2001). Canchildren's education and work be reconciled? International Journal of Educational Poluy, Research and Practice, 2(3), 307-330.

Mollo-Bouvier, S. (2005). Transformações dos modos de socialização das crianças: uma abordagem sociológica. Educação e Sociedade, 91(26), 391-403.

Moraes, R. V. (2007). A produção acadêmica sobre trabalho infantil: um olhar nos periódicos científicos brasileiros (1981-2004) (Dissertação de mestrado não-publicada). Programa de Pós-graduação em Ciências Sociais, Universidade Estadual de São Paulo.

Oliveira, D. C., Fischer, F. M., Martins I. S., \& Sá, C. P. (2001). Futuro e liberdade: o trabalho e a instituição escolar nas representações sociais de adolescentes. Estudos de Psicologia (Natal), 2(6), 245-258.

Oliveira, D. C., Sá, C. P., Fischer, F. M., Martins I. S., \& Teixeira, L. R. (2002). Representações sociais e fatores de risco para o trabalho infantil e do adolescente: uma aproximação possível. Cadernos de Saúde Pública, 2(10), 177-194. 
Oliveira, I. C. C., \& Francischini, R. (2003). A importância da brincadeira: o discurso de crianças trabalhadoras e não trabalhadoras. Psicologia: Teoria e Prática, 5(1), 41-56.

Paparreli, R. (2004). Trabalho precoce e escolarização: problematizando uma relação. In A. Garbin \& S. Santos (Org.), O compromisso do SUS naerradicação do trabalho de crianças e controle do trabalho de adolescentes (pp.129-157). São Paulo: CEREST.

Quinteiro, J. (2009). Infância e educação no Brasil: um campo de estudos em construção. In A. L. G. Faria, Z. B. F. Demartini \& P. D. Prado (Orgs.), Por uma cultura da infância: metodologias de pesquisa com criança (3a ed.). Campinas: Autores Associados.

Qvortrup, J. (2010). A infância enquanto categoria estrutural. Educação e Pesquisa, 2(36), 631-643.

Rosemberg, F., \& Freitas, R. R. (2002). Participação de crianças brasileiras na força de trabalho e educação. Educação e Realidade, 27, 95-125.

Rosemberg, F., \& Mariano, C. S. (2010). A convenção internacional sobre os direitos da criança: debates e tensões. Cadernos de Pesquisa, 141(40), 693-728.

Schwartman, S., \& Schwartman, F. (2004). Tendências do trabalho infantil no Brasil entre 1992 e 2002. Brasília: OIT.

Silva, R. (2001). Trabalho infantil e construção da identidade de gênero. Barbarói, 15(2), 83-111.

Sirota, R. (2001). Emergência de uma sociologia da infância: evolução do objeto e do olhar. Cadernos de Pesquisas, $112,7-31$
Sousa, S. M. G. (1999). Trabalho infantil:a negação da infância? Estudos (Goiânia), 1(26), 119-141.

Sousa, O. M. C. G., \& Alberto, M. F. P. (2008). Trabalho precoce e processo de escolarização de crianças e adolescentes. Psicologia em Estudo, 4(13), 713-722.

Spink, P. (1999). Análise de documentos de domínio público. In M. J. P. Spink (Org.), Práticas discursivas e produção de sentidos no cotidiano (pp. 123-151). São Paulo: Cortez.

Stengel, M., Castro, M. C. G., Marques, M. E., Moreira, M. I. C., Fazzi, C. F., \& Leal, R. S. (2002). Narrativas infanto-juvenis sobre o trabalho doméstico em Belo Horizonte: histórias de vida das meninas. Psicologia em Revista, 8(11), 125-129.

Streck, C. F., \& Frison, T. B. (1999). Lembranças de velhos: o mundo da infância. Estudos Interdisciplinares sobre o Envelhecimento, 1(1), 103-118.

Thompson, J. B. (2002). Ideologia e cultura moderna: teoria social crítica na era dos meios de comunicação de massa (6a ed.). Petrópolis: Vozes.

White, B. (1999). Defining the intolerable: Child work, global standards and cultural relativism. Childhood: A Global Journal of Child Research, 6(1), 133-144.

Woodhead, M. (1999). Combatting child labour: Listen to what the children say. Childhood: A Global Journal of Child Research, 6(1), 27-49.

Recebido em: 26/7/2011

Versão final em: 19/3/2012

Aprovado em: 27/3/2012 
Anexo

Principais categorias de análise observadas por artigo

\begin{tabular}{|c|c|c|c|c|c|c|}
\hline Autores e ano & Tipo de artigo & Faixa etária & Cor/raça & Escolaridade & Atividade & $\begin{array}{c}\text { Ouviu } \\
\text { crianças? }\end{array}$ \\
\hline Alberto e Santos, (2011) & Revisão & Apresenta & Não apresenta & Apresenta & Apresenta & Não \\
\hline $\begin{array}{l}\text { Alberto, Santos, Leite, Lima e Wanderley } \\
\text { (2011) }\end{array}$ & Relato de pesquisa & Não apresenta & Não apresenta & Apresenta & Apresenta & Sim \\
\hline Alves (2001) & Relato de pesquisa & Apresenta & Não apresenta & Apresenta & Apresenta & $\operatorname{Sim}$ \\
\hline Alves (2002) & Relato de pesquisa & Apresenta & Não apresenta & Apresenta & Apresenta & $\operatorname{sim}$ \\
\hline Artes e Carvalho (2010) & Relato de pesquisa & Apresenta & Apresenta & Apresenta & Apresenta & Não \\
\hline Campos e Alverga (2001) & ensaio & Não apresenta & Não apresenta & Não apresenta & Não apresenta & Não \\
\hline Campos e Francischini (2003) & Relato de pesquisa & Apresenta & Não apresenta & Apresenta & Apresenta & Sim \\
\hline Cirino e Alberto (2009) & Relato de pesquisa & Apresenta & Não apresenta & Não apresenta & Apresenta & $\operatorname{Sim}$ \\
\hline Cosendey (2002) & ensaio & Não apresenta & Não apresenta & Não apresenta & Não apresenta & Não \\
\hline Feitosa, Gomes e Gomes (2001) & Relato de pesquisa & Apresenta & Não apresenta & Apresenta & Apresenta & $\operatorname{Sim}$ \\
\hline Feitosa e Dimenstein (2004a) & Relato de pesquisa & Apresenta & Não apresenta & Apresenta & Apresenta & Não \\
\hline Feitosa e Dimenstein (2004b) & Relato de pesquisa & Apresenta & Não apresenta & Apresenta & Apresenta & Não \\
\hline Guerra (2002) & Relato de pesquisa & Apresenta & Não apresenta & Não apresenta & Apresenta & $\operatorname{Sim}$ \\
\hline Hillesheim (2001) & Relato de pesquisa & Não apresenta & Não apresenta & Não apresenta & Apresenta & $\operatorname{sim}$ \\
\hline Hillesheim (2004) & Relato de pesquisa & Apresenta & Não apresenta & Não apresenta & Apresenta & $\operatorname{Sim}$ \\
\hline Lopes (1986) & Relato de pesquisa & Apresenta & Não apresenta & Apresenta & Não apresenta & Sim \\
\hline Marques (1996) & Relato de pesquisa & Apresenta & Não apresenta & Não apresenta & Apresenta & $\operatorname{Sim}$ \\
\hline Marques (1998) & ensaio & Não apresenta & Não apresenta & Não apresenta & Não apresenta & Não \\
\hline Marques (2001) & Relato de pesquisa & Não apresenta & Não apresenta & Não apresenta & Apresenta & $\operatorname{Sim}$ \\
\hline Marques (2004) & Relato de pesquisa & Não apresenta & Não apresenta & Não apresenta & Apresenta & Não \\
\hline Martinez (2001) & Relato de pesquisa & Apresenta & Não apresenta & Não apresenta & Apresenta & Sim \\
\hline Oliveira, Fisher, Martins e Sá (2001) & Relato de pesquisa & Apresenta & Não apresenta & Apresenta & Não apresenta & $\operatorname{Sim}$ \\
\hline Oliveira, Sá, Fisher, Martins e Teixeira (2002) & Relato de pesquisa & Apresenta & Não apresenta & Apresenta & Não apresenta & $\operatorname{Sim}$ \\
\hline Oliveira e Francischini (2003) & Relato de pesquisa & Apresenta & Não apresenta & Apresenta & Apresenta & $\operatorname{Sim}$ \\
\hline Silva (2001) & Relato de pesquisa & Apresenta & Não apresenta & Não apresenta & Apresenta & Sim \\
\hline Sousa (1999) & Relato de pesquisa & Apresenta & Não apresenta & Apresenta & Apresenta & $\operatorname{Sim}$ \\
\hline Sousa e Alberto (2008) & Relato de pesquisa & Apresenta & Não apresenta & Apresenta & Apresenta & $\operatorname{sim}$ \\
\hline Stengel (2002) & Relato de pesquisa & Apresenta & Apresenta & Apresenta & Apresenta & $\operatorname{sim}$ \\
\hline Streck e Frison (1999) & Relato de pesquisa & Apresenta & Não apresenta & Não se aplica & Apresenta & Não \\
\hline
\end{tabular}

